Goad, H. \& L. White. (2009). Prosodic transfer and the representation of determiners in Turkish-English interlanguage. In N. Snape, Y-K. I. Leung \& M. Sharwood Smith (eds.), Representational deficits in L2 acquisition (pp. 1-26). Amsterdam: John Benjamins.

\title{
PROSODIC TRANSFER AND THE REPRESENTATION OF DETERMINERS IN TURKISH-ENGLISH INTERLANGUAGE*
}

\author{
Heather Goad and Lydia White \\ McGill University
}

\section{Introduction}

Problems with the second language (L2) acquisition of articles are well-documented, especially in the case of learners whose mother tongue (L1) lacks articles (Huebner 1985; Thomas 1989; Robertson 2000; Leung 2002; Snape 2006; amongst others). Two kinds of problems have commonly been identified, namely omission of articles in obligatory contexts, as in (1a), and overuse of one article in place of the other (usually definite in place of indefinite), as in (1b). (For both examples, the L1 is Turkish.)

(1) a. So brain is already shaped. (White 2003a)

b. She was holding the fork. (Goad \& White 2006a)

There have been various different approaches towards explaining and predicting these kinds of problems. Some focus on semantic factors, including the issue of overuse (e.g., Ionin 2003; Ionin, Ko \& Wexler 2004), or on discourse/pragmatic functions (e.g., Robertson 2000). In this paper, we offer an account in terms of prosodic representation, an account which explains article omission and a particular kind of substitution, namely the use of other determiners in place of articles, as well as other non-native aspects of article production related to stress. ${ }^{1}$

The issue of article underuse and overuse is potentially relevant to the debate over whether L2 speakers suffer from representational deficits and, if so, of what kind. In recent

\footnotetext{
* We would like to thank the following research assistants: Wid Al Bayaty, Will Dalton, Erin King, Moti Lieberman, Cornelia Loos, Jen Mah, Mizuki Mazzotta, Corrine McCarthy, Luisa Meroni, Monika Molnar, Jen Morehouse, Adèle-Elise Prévost, Chen Qu, Mari Umeda. Thanks as well to Shabana Ali for her artistic skills and to Natalie Batmanian, Ayșe Gürel, Nihan Ketrez, Öner Özçelik and Özge Öztürk for comments and judgments on Turkish. Special thanks to Ayșe Gürel for organizing the testing in Turkey. This research was funded by grants from SSHRCC and FQRSC.

${ }^{1}$ Our account does not speak to misuse of one kind of article for the other.
} 
years, proposals have focused on various sub-components of the grammar; properties of functional categories and their features have become a particular area of concern, with claims centring round presence or absence of impairment in this domain (e.g., Eubank 1996; Schwartz \& Sprouse 1996; Hawkins \& Chan 1997; Beck 1998; Lardiere 1998; Duffield et al. 2002; Tsimpli 2003).

An influential proposal in this vein is the Representational Deficit Hypothesis (RDH) (originally the Failed Functional Features Hypothesis) (Hawkins \& Chan 1997; Hawkins 2000, 2003; see also Tsimpli \& Roussou 1991; Tsimpli \& Mastropavriou 2007). According to the $\mathrm{RDH}$, adult L2 speakers fail to acquire uninterpretable formal features which are not realized in the $\mathrm{L} 1$ grammar, resulting in permanent misrepresentation of L2 features. This syntactic deficit has a number of consequences as far as overt inflection is concerned: Chinese-speaking learners of English are argued to be unable to acquire a tense feature (due to presumed absence of such a feature in Chinese) and, hence, have problems realizing tense morphology on verbs (Hawkins \& Liszka 2003); similarly, English-speaking learners of Spanish are argued to be unable to acquire gender (due to lack of a gender feature in English) and, hence, fail to fully master gender agreement within the DP (Franceschina 2001). The inability to acquire L2 uninterpretable features leads to omission of morphology in the case of tense, or inappropriate substitutions of one form for another in the case of gender.

In the present paper, we examine article production in L2 English speakers whose mother tongue, Turkish, has no definite article. English articles appear in DP and are associated with a definiteness feature (see section 2). If the L1 lacks this functional category and/or its associated features, then impairment might be anticipated, as Leung (2002) suggested for Cantonesespeaking learners of English and French. However, the RDH does not in fact expect features to fail in this case, the crucial feature - definiteness - being interpretable, rather than uninterpretable (Hawkins et al. 2006).

A different kind of syntactic representational deficit involving English articles is proposed by Trenkic (2004, 2007, in press). Trenkic assumes that learners whose L1s lack DP 
fail to analyse English articles as D elements, instead treating them as adjectives. She assumes (contra Hawkins et al. 2006) that definiteness is an uninterpretable feature in SpecDP. If so, according to the RDH, definiteness should not be acquirable. However, Trenkic does not attribute acquisition difficulties to uninterpretablility of features. Rather, according to her, the problem lies with the category D itself, as will be discussed below.

In the present paper, we also offer a representational account of L2 article production. We argue against Trenkic's syntactic misanalysis proposal. Instead, in accordance with the Prosodic Transfer Hypothesis (PTH) (Goad, White \& Steele 2003; Goad \& White 2004, 2006b), we propose that L1 prosodic representations are a major source of problems in L2 article production; furthermore, we will show that some aspects of non-native article suppliance can only be accounted for in prosodic terms.

\section{Articles and other determiners in English and Turkish}

Articles are functional elements which head the category D (Abney 1987); ${ }^{2}$ associated with them are a number of features. Choice of articles in English depends on the feature [ \pm definite], the being definite and $a$ indefinite. Turkish has only an (optional) indefinite article, unstressed bir, as shown in (2a) (Kornfilt 1997). In fact, there is disagreement amongst linguists working on Turkish on the status of unstressed bir. Kornfilt (1997) considers it to be an article, while Underhill (1976) treats it is a numeral. Lyons (1999) argues that it is neither; based on its meaning, he refers to it as a 'quasi indefinite article', but argues that definiteness is not grammaticalized in Turkish, a position adopted by Öztürk (2005) as well. We return to this issue below.

When bir is stressed, as in (2b), it is interpreted as the numeral one. In other words, depending on stress, the interpretation of bir varies between article and numeral (Erguvanli 1984; Kornfilt 1997; Öztürk 2005; amongst others). Like English, Turkish has other determiners which

\footnotetext{
${ }^{2}$ There is disagreement as to whether both articles head D. On some accounts, definite and indefinite articles head different functional projections (e.g., Lyons 1999).
} 
are stressed, such as quantifiers, demonstratives, numerals and possessives, as in (2c). Finally, in contexts where English would require an overt article, Turkish also allows bare nouns, as in (2d). The interpretation of a bare noun as definite or indefinite depends on a number of factors, including word order and case-marking. Bare nouns typically receive a definite interpretation in subject position and are potentially ambiguous elsewhere.
(2) a. bir kitáp b. bír kitap
c. bú kitap 'this book'
d. kitáp 'a/the book'

\subsection{Prosodic representation of articles and other determiners in English and Turkish}

In this paper, we are particularly concerned with cross-linguistic differences in the prosodic organization of articles and the consequences this has for L2 acquisition. In (3a), the prosodic representation for English definite and indefinite articles is shown; these link directly to the phonological phrase (PPh) as 'free clitics' (Selkirk 1996). Phonological considerations have led us to conclude that Turkish does not permit free clitics anywhere in the grammar (see section 3.1); that is, Turkish lacks the representation in (3a) for functional material at either edge of its host. Instead, unstressed bir is adjoined to the prosodic word (PWd) of its host as an 'affixal clitic', as shown in (3b), the typical representation for prefixes across languages (e.g., Peperkamp 1997). 
(3) Articles:
a. English definite and indefinite: free clitic:

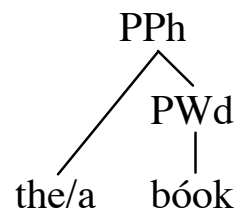
b. Turkish indefinite: affixal clitic/prefix:

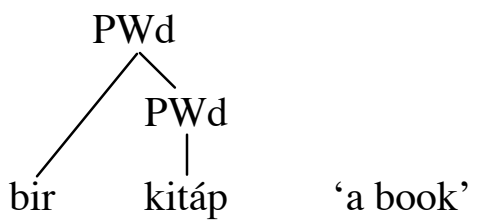

Other determiners in both English and Turkish, including the numeral bir, are stressed and thus form independent PWds, as shown in $(4 a-b){ }^{3}$

(4) Other determiners: independent PWds:
a. English:
b. Turkish:
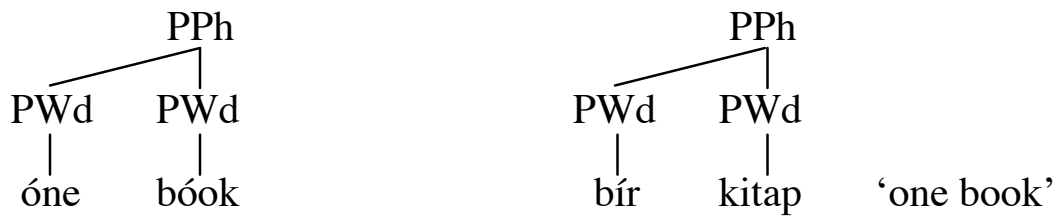

As we have previously argued (Goad \& White 2004), word order in DPs containing adjectives provides evidence for the differing representations of English and Turkish articles. Turkish bir appears in a different position in relation to the adjective, depending on whether it is a numeral or an article (e.g., Kornfilt 1997; Öztürk 2005). When bir is a numeral (i.e., stressed), like English one, it precedes the adjective, as shown in (5).

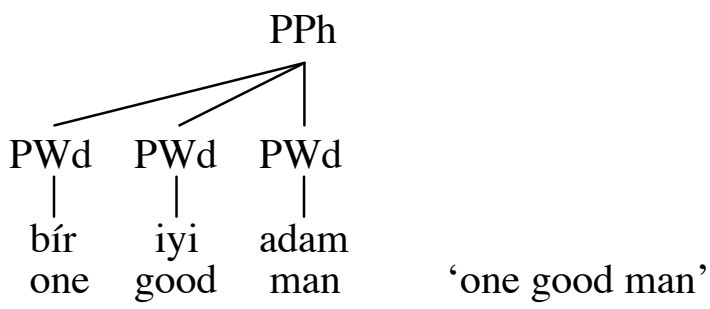

\footnotetext{
${ }^{3}$ The Turkish examples in (4)-(6) mark phrasal stress only, because Turkish speakers disagree on the status of secondary stress. We have followed Kabak \& Vogel (2001) who state that main stress falls on the leftmost word in the phrase, as this corresponds to the judgments received from the native speaker informants that we consulted about stress. There is, however, disagreement in the literature on this; see Inkelas \& Orgun (2003) for a different view.
} 
However, when bir is an indefinite article (unstressed), it follows the adjective. Thus, (6a) is a possible representation but (6b) is not because, as a prefix, indefinite bir must cliticize onto the noun that it modifies. ${ }^{4}$

(6) a.

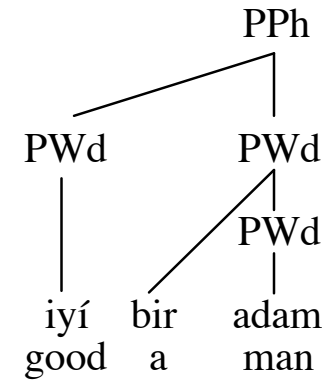

'a good man'

b.

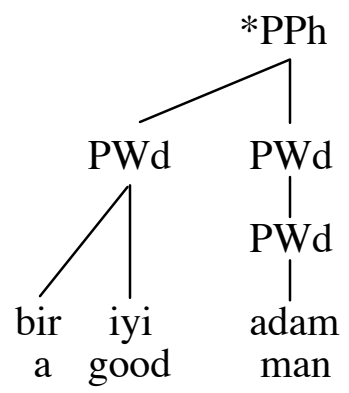

In English, no such change in word order is observed: the presence of an adjective has no effect on the position of articles, indicating that articles link higher in the structure, at the level of the $\mathrm{PPh}$, as shown in (7).

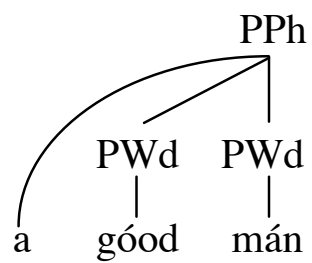

In short, the non-canonical word order observed in Turkish constructions with adjectives and unstressed bir would be unexpected if unstressed bir had the same prosodic representation as English articles.

Öztürk (2005) states that other numerals and determiners in Turkish also alternate, appearing before or after adjectives, as shown in (8).

\footnotetext{
${ }^{4}$ The representation in (6a), where indefinite bir adjoins to the PWd, can be motivated for determiners in other languages as well. Poser (1990) argues that in Japanese, Aoyagi "pre-nominal modifiers", some of which have the semantics of determiners, are organized as prefixes; one piece of evidence for this is that adjectives cannot intervene between these "modifiers" and nouns, in contrast to the behaviour of other determiners in the language (see also Snape 2006).
} 
(8) a. bu kırmızı kitap this red book

b. k1rmızı bu kitap red this book

c. iki kırmızı kitap two red books

d. k1rmızı iki kitap red two books

However, we have observed that this alternation differs from the alternation involving bir. Firstly, there is a preference for the word order where the determiner precedes the adjective, as in (8a) and (8c). Secondly, while there are subtle meaning differences associated with this alternation, they do not involve the determiner itself, nor do they depend on whether or not the determiner is stressed. We conclude, therefore, that only bir shows an alternation which is prosodically conditioned.

\subsection{Syntactic representation of articles in Turkish}

There is considerable debate amongst linguists working on Turkish as to the representation of noun phrases, in particular, as to whether or not Turkish has a DP projection. Öztürk (2005) proposes that Turkish lacks DPs altogether. She treats unstressed bir as an adjective-like modifier within NP. ${ }^{5}$ A related analysis is assumed by Trenkic $(2004,2007$, in press) for Serbian. She argues that there is no DP in languages where definiteness is not grammaticalized in an article system. Like Öztürk, she assumes that Turkish is such a language. Trenkic follows Lyons (1999) in assuming that the D position and a definiteness feature are associated only with definite articles, which Turkish lacks; indefinites are associated with a different functional projection, namely cardinality.

This is not the place to go into details on the debate over NP versus DP in Turkish. Suffice it to say that Trenkic advances the NP analysis for interlanguage grammars as well, in situations where the L1 lacks a DP projection. She claims that L2 learners of English whose L1

\footnotetext{
${ }^{5}$ Öztürk (2005) considers stressed bir to be an adverbial modifier of a complex predicate.
} 
is Serbian or Turkish fail to project a DP, misanalysing English articles as adjective-like modifiers. This misanalysis, together with pragmatic factors (see section 4), accounts for problems with L2 articles.

If languages like Serbian and Turkish indeed lack DP and if article-like elements are in fact adjectives, this analysis has important prosodic consequences. The crux of the matter is that adjectives, as lexical elements, must form independent PWds.

As detailed in Zec (2005), lexical elements (including adjectives) in Standard Serbian always form their own PWds, making them bearers of both pitch and stress (Serbian is a pitch accent language). Bisyllabic free functional elements, including a subset of determiners, also form PWds; they receive pitch accent but cannot be stressed (unless under focus). Monosyllabic free functional elements, including another subset of determiners, do not form PWds; they are free clitics, and are thus represented like articles in English, namely with the representation in (3a). As expected, they do not receive pitch accent and cannot be stressed (focus aside). If determiners in general are analysed as adjectives in Serbian, these contrasts would be lost; all determiners should form PWds and receive pitch accent. In other words, under this view, Serbian would not permit any determiners to be organized as free clitics, contrary to fact.

Turning to Turkish, if bir is analysed as an adjective, it should also form its own PWd. Such an analysis, however, cannot account for the fact that bir, when interpreted as the indefinite article, is unstressed. Rather, bir should always receive main stress when in phrase-initial position, regardless of its interpretation. In other words, the difference in prominence pattern between bír kitap 'one book' in (2b) and bir kitáp 'a book' in (2a) would be lost.

To summarize, English and Turkish differ morpho-syntactically and prosodically. English realizes a [ \pm definite] distinction overtly in the article system (the versus $a$ ). Articles are prosodically realized as free clitics, attached directly to the PPh. In Turkish, on the other hand, there is no morphological realization of the definite article (although other determiners such as possessives and demonstratives are definite, as they are in English). Unstressed bir is [-definite]; prosodically, it is organized as an affixal clitic, adjoined to the PWd. As far as the syntactic 
representation of Turkish unstressed bir is concerned, we suggest that the evidence from interpretation, prosodic characteristics and positioning relative to nouns with and without adjectives favours the article analysis over an analysis as some other type of modifier, and that this is true of interlanguage articles as well.

\section{Prosodic Transfer Hypothesis (PTH)}

In earlier work, we proposed the Prosodic Transfer Hypothesis (Goad, White \& Steele 2003; Goad \& White 2004, 2006b), according to which L1 prosodic representations are (at least in part) the determinants of success or lack of success in spoken production of L2 inflection and function words. L2 learners are predicted to have difficulty in accurately producing functional morphology when the $\mathrm{L} 2$ requires a prosodic representation which is unavailable in the L1 (or unavailable for the target construction).

In previous work, we have shown that prosodic transfer constrains the production of English articles, as well as tense and agreement morphology, for Mandarin speakers (Goad, White \& Steele 2003; Goad \& White 2006b, in press). We have also shown in a case-study of an endstate L2 Turkish-English speaker (known as SD) that article suppliance was comparatively low and that there was a significant contingency between presence of an adjective and omission of articles (White 2003a; Goad \& White 2004). In other words, there was some support for the claim that the representation in (3a) is problematic for Turkish-speaking learners of English, thereby supporting the PTH. However, the data came from only one subject and we did not examine other properties of her article suppliance, such as whether or not articles were stressed. In this paper, we examine article suppliance in the L2 English of a number of Turkish speakers, at various levels of proficiency, using a task designed to more systematically elicit some of the patterns we observed in the original study, particularly the interaction of articles and adjectives. 


\subsection{General predictions of PTH}

Given the differences in the prosodic organization of articles in English and Turkish discussed above, the PTH predicts that Turkish speakers should have difficulty constructing the target representation for articles in English. This should affect definite and indefinite articles alike, since they are prosodified in the same way in the L2; that is, difficulties should hold for both articles, independent of the fact that only an indefinite article is realized in the L1 grammar.

When the target prosodic representation is not present in the $\mathrm{L} 1$ grammar, as in the case of Turkish, high rates of article deletion are expected, especially at low levels of proficiency. As proficiency improves, we expect learners to become aware of the need for overt articles in the L2; hence suppliance should increase. However, we anticipate various non-target strategies in outputs, all of which have as their source the prosodic constraints of the L1 (see section 3.2).

Concerning the potential for native-like suppliance of English articles, we have argued in earlier work that target prosodic representations can be built in the interlanguage grammar under two conditions (see (9)), both of which involve minimally adapting L1 representations that occur in other constructions (Goad \& White 2004). Specifically, new structures are possible:

(9) a. when they can be built through combining pre-existing (L1) licensing relations; or b. when they involve L1 structures being licensed in new positions.

Support for this proposal came from a comparison of SD's rates of suppliance of tense, agreement and plural morphology versus articles in English. In the former case, it was possible to minimally adapt structures from Turkish; target-like prosodic representations could thereby be built and rates of suppliance in English were correspondingly high.

In the case of articles, however, no adaptation of L1 structures is possible to allow the representation in (3a) (see discussion below) and rates of suppliance were correspondingly lower. As mentioned in section 2, Turkish does not permit free clitics at either edge for other constructions in the language, thus precluding the adoption of the structure for English articles 
through condition (9b). Left-edge free clitics seem to be absent altogether from Turkish; that is, every PPh must start with a PWd (either a lexical element, a stressed functional element (e.g., stressed bir), or a prefix (e.g., unstressed bir)). While Kornfilt (1997) analyses a number of bound elements at the right-edge as syntactic clitics, there is phonological evidence that they are not directly linked to the $\mathrm{PPh}$.

A case in point is provided by inflected forms of the copula $-y$. Kornfilt analyses these as clitics because they undergo vowel harmony but display exceptional 'prestressing' behaviour (e.g., Hasan dün hastá-y-dı Hasan yesterday sick-COP-PAST 'Hasan was sick yesterday' (p. 436)). Kornfilt does not address how these elements are organized into prosodic structure. However, to capture their prestressing behaviour, Kabak \& Vogel (2001) and Newell (2005) argue that they are adjoined to the PWd ([[hastá $\left.\left.]_{\mathrm{PWd}}-\mathrm{y}\right]_{\mathrm{PWd}}\right) ;^{6}$ indeed, Kabak \& Vogel explicitly argue against their being attached to the $\left.\mathrm{PPh}\left(*\left[{ }^{2} \text { hastá }\right]_{\mathrm{PWd}}-\mathrm{y}\right]_{\mathrm{PPh}}\right)$. Since the domain of vowel harmony is the lower PWd in the vast majority of languages (cf. van der Hulst \& van de Weijer 1995) and evidence from compounds supports this view for Turkish (cf. Kabak \& Vogel 2001), we consider that elements such as copular $-y$ must be internal to the domain of their host in order to fall within the scope of harmony ([hastá-y $\left.]_{\mathrm{PWd}_{\mathrm{d}}}\right)$. In short, although there is some disagreement about the organization of these elements, as PWd-internal or as adjoined, it is agreed that they are not linked to the $\mathrm{PPh}$ as free clitics.

Turning to minimal adaptation under condition (9a), in Goad \& White (2006b), we detail how L1 licensing options cannot be combined to build a structure where articles link directly to the $\mathrm{PPh}$ because languages will only allow a syllable to associate directly to this constituent if the syllable, underlined in (10a), is functional.

\footnotetext{
${ }^{6}$ This is somewhat of a simplification. Kabak \& Vogel argue that clitics as well as suffixes that display exceptional stress are organized into the Clitic Group. For present purposes, this can be equated with the recursive PWd structure provided in the text for hastá-y.
} 
(10)

a. Free clitic:

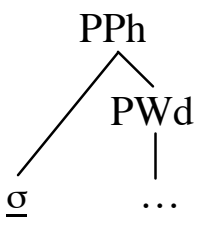

b. Affixal clitic:

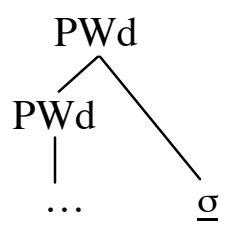

Consider the category PWd for comparison. This category is unique in its ability to organize both lexical and functional material. Accordingly, prosodic representations for lexical material in the L1 can be adapted to represent functional morphology in the interlanguage. Concerning English inflection, for example, the necessary adjunction structure for the inflectional syllable, underlined in (10b), can be built in the Turkish-English interlanguage grammar by combining existing representations from the $\mathrm{L} 1$ grammar: $\mathrm{PWd}$ recursively dominating $\mathrm{PWd}(\mathrm{PWd}-\mathrm{PWd})$, a structure required for lexical compounds, and PWd directly dominating $\sigma(\mathrm{PWd}-\sigma)$, a structure required at the right edge to capture non-final stress in a subset of the Turkish vocabulary sometimes referred to as 'Sezer stems' (mostly place names and foreign proper names) (cf. Sezer 1981). As most languages are like Turkish in having both lexical compounding and permitting syllables in lexical words to link directly to the PWd under some condition or other, learners from most L1s lacking adjunction will be in a position to build the structure required for inflection in English-type languages under condition (9a). Returning to the structure in (10a) required for English articles, this structure is impossible to build from existing L1 licensing relations because - unlike the case of the $\mathrm{PWd} \mathrm{-} \mathrm{a} \mathrm{syllable} \mathrm{can} \mathrm{only} \mathrm{link} \mathrm{directly} \mathrm{to} \mathrm{the} \mathrm{PPh}$ if the syllable is functional. Hence, if an L1 grammar lacks $\mathrm{PPh}-\sigma$, as Turkish appears to, it will be impossible to build this licensing relation under condition (9a).

To summarize, the absence of free clitic constructions in Turkish should prevent learners from building this structure for English articles under either of the conditions in (9). In other words, the strongest interpretation of the PTH is that the target prosodic structure for English articles will not be acquirable by Turkish speakers. A weaker interpretation is that this structure should be particularly difficult to acquire, only emerging in the grammars of particularly 
proficient learners. Under either view, for all but perhaps the most proficient speakers, we expect a number of non-target productions in article contexts, which have as their source the prosodic constraints of the L1.

\subsection{Predicted non-target productions}

In this section, we detail the various strategies that speakers are predicted to adopt for the interlanguage production of articles. If Turkish-speaking learners have not acquired (or possibly cannot acquire) the free clitic structure for representing English articles, these strategies should be robustly attested in outputs, depending in part on level of proficiency.

Perhaps the 'easiest' way to avoid the English free clitic representation in (3a) is to omit articles altogether, instead producing bare nouns. The result is the prosodic representation in (11) which is, of course, well-formed for bare nominals in Turkish and English, although inappropriate in contexts requiring articles. As mentioned earlier, we expect deletion to be particularly common at low levels of proficiency.

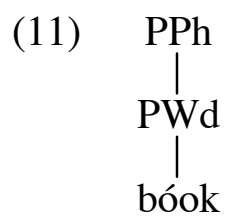

Alternatively, the representation in (3a) can be avoided by stressing the article or by substituting some other stressed determiner. In both cases, the presence of stress requires that the determiner be organized as an independent PWd, as shown in (12); this representation is permitted in Turkish as well as in English (see (4)).

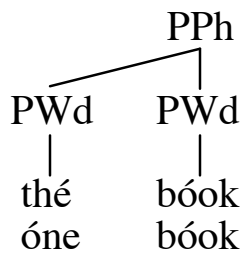


It is also possible that learners will be able to produce seemingly target-like unstressed articles, by using the Turkish affixal clitic representation in (3b) required for unstressed bir. In most contexts where unstressed articles are produced, it will be impossible to determine which structure is adopted, that is, whether L2 speakers have acquired the target representation in (3a) or whether they continue to use the transferred representation in (3b). However, given the word order alternation shown in (5) and (6) above, English DPs containing adjectives can be used to determine the interlanguage representation of unstressed articles. If subjects have acquired the appropriate representation for prosodifying articles as free clitics, namely (3a), no problem should arise in the context of adjectives. If, on the other hand, they represent articles as affixal clitics, as in (3b), the PTH predicts problems in DPs containing adjectives. We do not expect speakers to adopt the Turkish word order (adjective article noun, as in (6a)), since this would violate the syntactic structure of English. ${ }^{7}$ Instead, we predict an asymmetry in suppliance of unstressed (target-sounding) articles in contexts with and without adjectives. In particular, articles that are unstressed should be supplied less frequently in DPs with adjectives than in DPs without adjectives. This is because affixal clitics must prefix onto the head noun, something which can only be achieved if the article directly precedes the noun, and not if it directly precedes an adjective, as shown in (13), repeated from (6b).

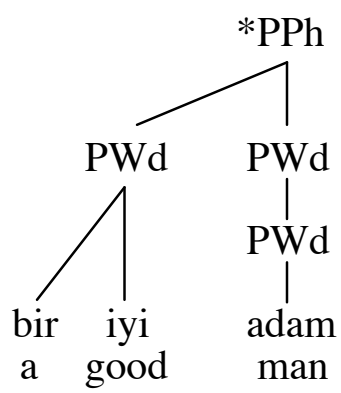

\footnotetext{
${ }^{7}$ On Trenkic's account, articles are treated as adjectives in Serbian-English and Turkish-English interlanguage because of L1 transfer. The adjectival status of determiners in the L1 is, in part, motivated by the fact that word orders like (8b) and (8d) are possible in Serbian (Trenkic 2004: 1412), as well as Turkish. Given such a syntactic misanalysis, then, one might expect adjective article noun word order to show up in the interlanguage. Trenkic does not discuss this possibility and it is not clear how she could rule it out.
} 
In consequence, deletion and stressing of articles, as well as substitution of other determiners in place of articles, are all expected to be higher in the presence of adjectives.

\section{An alternative hypothesis on the representation of L2 articles}

\subsection{Syntactic misanalysis}

Trenkic (2007) argues that treatment of articles in L2 English cannot be accounted for by the PTH because learners whose L1 is Serbian omit articles more in the context of an adjective, even though the representation required for English articles is available in the L1 for a subset of determiners (Zec 2005). Since prosodic transfer should help rather than hinder in this case, an asymmetry between contexts with and without adjectives is unexpected. Further, the asymmetry is found in written as well as oral production, suggesting that prosodic structure cannot be implicated.

Trenkic accounts for the observed behaviour in her own and previous studies in terms of a representational deficit together with processing pressures largely relating to pragmatic factors. In particular, learners whose L1s lack DP fail to analyse English articles as D elements and instead misanalyse them as adjectives, with meanings associated with identifiability (definite, in the case of the, and indefinite, in the case of $a$ ). Deletion of articles occurs because pragmatically redundant information is liable to be omitted under communication pressure. Overt expression of definiteness is largely redundant because there will be other cues to identifiability in the context. Hence, articles in general are subject to omission. Furthermore, when another adjective is present, this increases the complexity of the utterance, making it even more likely that articles will be omitted, since they are generally less informative than other adjectives. In addition, Trenkic states that indefinite articles are more likely to be omitted than definite because they require greater computational resources than definite articles, since they encode not only identifiability but also number and countability. Finally, Trenkic argues that there are certain 
contexts which favour redundancy; hence, article omission is particularly likely to occur. This includes 'given' or old information; that is, articles are more likely to be omitted from NPs that are topics or that have previously been introduced into the discourse than from NPs introducing new information. ${ }^{8}$

Note as well that if articles are in fact adjectives, they should invariably be produced as prosodically prominent (bearers of pitch or stress), as discussed in section 2.2. Concerning Serbian-English interlanguage, we assume that this is not the case, since Trenkic does not mention it. As we will see below, it is also not the case in Turkish-English interlanguage. Stress on articles is common but it is not inevitable.

\subsection{Predictions of two accounts of article representation}

Table 1 summarizes the predictions of the two approaches to article representation under discussion. Article omission is expected, although for different reasons, by both the PTH (in order to avoid a particular prosodic representation) and by the syntactic misanalysis account (in response to communication pressure). Stressing of articles and substitutions of other determiners in place of articles is predicted by the PTH; the reason for these options is again prosodic, in order to avoid (3a). Stressing of all articles is in fact predicted by the syntactic misanalysis account, although Trenkic does not consider this prediction. Problems with articles in adjectival contexts are predicted by both the syntactic misanalysis account (which expects article deletion) and by the PTH (which expects a variety of options to be displayed in learners' productions, including - but not limited to - deletion). Greater omission of indefinite articles in general is predicted by the syntactic misanalysis approach, particularly differential treatment of articles in the context of old versus new information, such as topics or previous mention in the discourse.

\section{Table 1 here.}

\footnotetext{
${ }^{8}$ In fact, as far as we can tell, these claims about effects of redundancy do not depend on the misanalysis of articles as adjectives and could just as easily be made if articles are analysed as articles (see, for example, Robertson 2000).
} 
In the following sections, we report on an experiment testing the predictions of these two approaches to article representation. We examine the treatment of articles in the L2 English of Turkish speakers, considering the extent to which their behaviour supports a prosodic account over syntactic misanalysis.

\section{Experiment}

\subsection{Methodology}

The experiment involved 18 Turkish-speaking learners of English, whose proficiency level (determined by means of a cloze test and self-report) was low $(n=9)$, intermediate $(n=7)$ and advanced $(n=2) .{ }^{9}$ Mean age of the subjects at time of testing was 22.5 years, range 16-33. Six subjects were living in Canada and were tested there; mean length of residence was 2.5 years, range 6 months to 6 years. Twelve subjects (none of whom had ever resided in an Englishspeaking country) were tested in Turkey. With one exception, all subjects were currently university students; all of them had learned some English in secondary school (in Turkey) and the majority were currently taking an English course at university (in Turkey or in Canada). ${ }^{10}$

The experiment used an elicited production task, involving a sequence of pictures telling a story. The story was designed so that a variety of nouns and adjectives would (hopefully) be elicited, including the use of pictures which contrasted two items (e.g., a small girl and a taller girl; a red balloon and a blue one). Subjects had to describe what was happening in their own words. They were taped using a SONY PCM-M1 DAT recorder. The data were subsequently transcribed and coded in two different ways: (i) syntactic coding, which coded presence or absence of articles, substitutions, what article would be expected in the context, etc.; (ii) narrow

\footnotetext{
${ }^{9}$ Unfortunately, numbers in each group are unbalanced as we were unable to find sufficient subjects at an advanced level of proficiency.

${ }^{10}$ One of the intermediate-level subjects, T13, attended a German-medium secondary school in Turkey and reported himself as a near-native speaker of German. German has articles which, in at least one construction (in sentences with topicalized NPs), can be organized in the same fashion as in English (Kupisch et al. to appear). This may have contributed to his relatively strong performance.
} 
phonetic transcription, which focused on correlates of stress. ${ }^{11}$ Orthographic transcription and syntactic coding were carried out by native speakers or near native speakers of English and checked by three native speakers; coders showed a high degree of consistency. ${ }^{12}$ Phonetic transcription and coding was carried out by a native speaker of English with extensive training in phonetic transcription. A second native speaker of English with significant training in phonetic transcription re-transcribed data from every subject (20\% to $100 \%$ of the data, depending on sample size). The inter-transcriber reliability was $88.4 \%$ (range $80 \%-100 \%$ ).

\subsection{Results}

We restrict our analysis to DPs with singular count nouns, since these require an article (or other determiner) in English; in other words, they cannot be bare, unlike indefinite plurals and mass nouns. The task yielded an average of 111 such contexts per subject (range: 61-204).

Results from DPs without adjectives are presented in Figure 1, which shows the patterns of suppliance for definite and indefinite contexts taken together (since they have the same prosodic representation). Subjects are organized by proficiency level; within each proficiency group they are organized in terms of proportion of suppliance of target-like forms. Non-target productions include omission of articles, as well as stressing of articles and substitution of other determiners in place of articles. ${ }^{13}$ Target-like productions are unstressed. ${ }^{14}$

\footnotetext{
${ }^{11}$ The vowel in an article was coded as stressed when it was perceived as having higher than target-like pitch, greater than target-like duration and/or greater than target-like loudness (based on narrow transcription). Our transcribers were trained to pay particular attention to all of these factors. Note that F0 contour is the principal acoustic cue for stress in both Turkish and English; English relies secondarily on duration while Turkish relies on intensity (e.g., Fry 1958; Lehiste 1976 versus Konrot 1981; Levi 2005).

${ }^{12}$ The study included no native speaker controls. However, the coding by native speakers effectively provided controls, since coders indicated whether or not utterances were grammatical, which articles were appropriate and which not, etc.

${ }^{13}$ In addition, articles were sometimes produced followed by pauses or fillers which has the effect of breaking up the representation and thereby averting the target prosodic structure we are interested in. However, there are many different reasons why L2 speakers (and indeed native speakers) might insert pauses or fillers, for example, for reasons of lexical retrieval. For this reason, these items have been excluded from the analyses.

${ }^{14}$ Target-like productions are unstressed, but they may not, in fact, involve the target representation; recall that article + noun constructions will sound target-like if either of the representations in (3a) or (3b) is used. DPs with intervening adjectives will help to tease apart these options.
} 
As can be seen, omission of articles is robustly observed for all of the low proficiency subjects and for three of the intermediate group (T16, T8, T15), ranging from $20 \%$ to $80 \%$ of their article contexts. The omission rates of the remaining subjects were low (10\% or less). Almost all subjects (with the exception of T15 and T2) produce a sizeable proportion of stressed articles, ranging from $15 \%$ to $40 \%$ of their productions. As for target-like articles, both of the advanced subjects (T6, T2) and five of the intermediate group (T15, T3, T9, T13, T1) produced a majority of DPs with unstressed articles, ranging from $61 \%$ to $87 \%$ of their DPs.

\section{Figure 1 here.}

Amongst non-target productions, omission of articles (as in (14)) and stressing of articles (underscored, as in (15)) were the most frequently-attested patterns. Inappropriate substitutions, such as one in place of $a$ (see (16)) and this or that in place of the, were less common. ${ }^{15}$

(14) Susan ... reading book (T18)

(15) a man and a girl (T10)

(16) and one girl is serving something (T17)

For five of the seven subjects who produced more target-like articles than non-target (T3, T9, T13, T1, T6), stressing predominated over deletion in non-target productions (20\%-29\%) stress versus 4\%-9\% deletion); one subject (T15) produced more deletion (28\%) than stress $(8 \%)$; the seventh subject (T2) produced very few deletions or stressed forms. The behaviour of most of these subjects suggests that they are aware that English singular count nouns require overt articles.

There is a significant positive correlation $(\mathrm{r}=.813 ; \mathrm{p}<.001)$ between rate of target-like suppliance in DPs without adjectives and proficiency level (as determined by the cloze test alone), with low proficiency subjects showing the lowest proportion of target-like forms and

\footnotetext{
${ }^{15}$ We restrict the term substitution here, reserving it for substitutions of other determiners in place of articles. We return to overuse of definite for indefinite, and vice versa, below.
} 
higher proficiency subjects producing correspondingly more. This raises the question of whether the higher proficiency subjects have indeed acquired the target representation. For this reason, we turn now to a consideration of DPs with singular count nouns containing adjectives, in order to see whether target-like productions drop in the context of an adjective; these results are presented in Figure 2. (Note that only one subject produced substitutions of other determiners in DPs with adjectives, so substitutions have been omitted from this analysis.) Several subjects are excluded because they did not produce sufficient adjectives for a comparison to be possible, despite our attempts to elicit them, leaving 13 subjects for this analysis. Excluded subjects were all from the lowest proficiency group, namely T18, T17, T5, T12, T4. ${ }^{16}$

Recall that we predict greater problems with these DPs if L2 speakers are adopting the L1-based affixal clitic representation in (3b). While this representation is viable in the absence of an adjective and will in fact sound target-like, it is illicit in contexts where adjectives intervene between the article and noun.

\section{Figure 2 here.}

A comparison of Figures 1 and 2 reveals that a number of subjects show behaviour in the predicted direction. In other words, in the context of an adjective, their suppliance of unstressed articles falls and they produce correspondingly more non-target forms involving deletion or stressing. The examples in (17) illustrate deletion and stressing in the presence of adjectives.

(17) a. She has pink ... skirt. (T15)

b. Susan uh bought the ... uh red one and the yellow hat. (T16)

Chi-square tests show that for 7 of the 13 subjects for whom the adjective analysis was possible, the contingency between presence of an adjective and non-target-like article production was significant or neared significance $\left(\mathrm{T} 10: \chi^{2}=3.795, \mathrm{p}<.05 ; \mathrm{T} 11: \chi^{2}=5.674, \mathrm{p}<.02\right.$; T7:

\footnotetext{
${ }^{16}$ Exclusion criteria were as follows: fewer than 12 adjectives produced and/or production of DPs with adjectives was less than $12 \%$ of total DPs.
} 
$\chi^{2}=3.337, \mathrm{p}<.0677 ; \mathrm{T} 14: \chi^{2}=4.326, \mathrm{p}<.05 ; \mathrm{T} 8: \chi^{2}=11.792, \mathrm{p}<.001 ; \mathrm{T} 3: \chi^{2}=16.536, \mathrm{p}<.0001 ; \mathrm{T} 6:$ $\left.\chi^{2}=4.798, \mathrm{p}<.05\right) .{ }^{17}$ However, in the case of T14, the contingency is in the wrong direction, for which we have no explanation. The observed effect cannot be attributed to proficiency, amount of L2 input or to type of exposure to English, since a contingency was found at all levels of proficiency and for two of the six subjects who were living in Canada (T3, T6).

Let us consider the contingency data in more detail, in terms of how target-like overall performance was on DPs without adjectives. These results are summarized in Table 2. Six of the subjects for whom this comparison is possible (T10, T11, T7, T14, T16, T8) produce unstressed articles $49 \%$ of the time or less in DPs without adjectives. A comparison of their target-like productions in Figs 1 and 2 shows that four of these subjects (T10, T11, T7, T8) have the predicted asymmetry in the right direction, in other words, omitting or stressing articles significantly more in the presence of an adjective. As previously mentioned, T14 shows the asymmetry in the wrong direction, while T16 shows no significant contingency. Four subjects (T15, T3, T9, T13) showed target-like productions ranging from 61-68\% when no adjective was present; of these subjects, two (T3, T6) show the expected asymmetry. Finally, three subjects (T13, T1, T2) produced a substantial majority of target-like forms (70\% or higher) when no adjective was present. If their target-like productions are indeed truly on target (that is, using the representation in (3a) rather than (3b)), no asymmetry is expected between performance on DPs with and without adjectives. This expectation holds for all three of them. (Note that T13 is the subject who reported being near-native in German, so possibly we are seeing beneficial effects from L2 to L3 here.)

\section{Table 2 here.}

To summarize, results show that non-target production is common, especially in subjects of lower proficiency. Omission and stressing are found, as well as some cases of substitution. Furthermore, when apparently target-like unstressed articles are produced, a comparison of DPs

\footnotetext{
${ }^{17}$ We recognize that the chi-square results must be interpreted with caution, as the observations are not fully independent.
} 
involving adjectives with DPs that do not contain adjectives suggests that unstressed articles are represented with the Turkish structure (3b) rather than the English one (3a) for approximately half of the 13 subjects for whom this analysis was possible. The number of subjects who show no contingency between presence of an adjective and target-like production of articles increases as target-like performance on articles in DPs without adjectives increases.

\subsection{Syntactic misanalysis revisited}

We turn now to omission of articles in more detail, looking at two claims of Trenkic's (2007) syntactic misanalysis account, namely: (i) indefinite articles should be omitted more than definite; (ii) articles are more likely to be omitted from NPs which are topics or which have been previously mentioned in the discourse.

\section{Table 3 here.}

Table 3 compares omission of definite and indefinite articles. It can be seen that there are some subjects who omit indefinites more than definites, some who omit definites more than indefinites and some who show no difference. The subjects for whom the contingency between definiteness and omission is significant are T18 $\left(\chi^{2}=3.869, \mathrm{p}<.05\right), \mathrm{T} 10\left(\chi^{2}=13.178, \mathrm{p}<.001\right)$, T11 $\left(\chi^{2}=13.973, \mathrm{p}<.001\right), \mathrm{T} 15\left(\chi^{2}=4.73, \mathrm{p}<.05\right)$ and T13 $\left(\chi^{2}=7.979, \mathrm{p}<.01\right)$, who, contrary to Trenkic's prediction, omit a higher proportion of definite articles, and T4 $\left(\chi^{2}=12.885, \mathrm{p}<.001\right)$, T16 $\left(\chi^{2}=3.986, \mathrm{p}<.05\right)$ and T2 $\left(\chi^{2}=5.337, \mathrm{p}<.02\right)$, who omit a higher proportion of indefinites. Perhaps crucially for Trenkic's claim that articles are more often deleted in the context of adjectives for reasons of computational pressure, of the six subjects who showed the relevant contingency between presence of adjectives and omission/stressing of articles (T10, T11, T7, T8, T3, T6; see Table 2), only two (T10, T11) show a significant difference in omission depending on definiteness, both in the wrong direction. This suggests that omission of articles before 
adjectives is independent of supposed difficulties in computation for the Turkish-speaking learners of English under discussion.

In addition, article omission does not correlate with whether or not the NP is a topic (Table 4) or whether or not first mention is involved (Table 5). According to Trenkic's account, article deletion is expected to be higher in the case of NPs expressing topics and with NPs involving subsequent mention, because any lexical meaning conveyed by the article is less critical in these cases, since they convey old information. Table 4 compares the percent article suppliance in the case of preverbal subjects (standardly taken to be topics) with NPs that are not subjects. It can be seen that the proportion of overt articles with subjects and non-subjects is, by and large, similar. Only three participants (T10: $\chi^{2}=4.013, \mathrm{p}<.05 ; \mathrm{T} 13: \chi^{2}=9.114, \mathrm{p}<.01$; T2: $\left.\chi^{2}=4.747, \mathrm{p}<.05\right)$ show a significant contingency between suppliance of an article and the topic/subject status of the NP, and for two of these (T13, T2), the contigency is in the opposite direction to that predicted by Trenkic.

\section{Table 4 here.}

Table 5 looks at whether an NP provides first or subsequent mention of the referent in question. Suppliance of an overt article is independent of first mention for almost all participants. Again, only three participants $\left(\mathrm{T} 10: \chi^{2}=12.201, \mathrm{p}<.001 ; \mathrm{T} 11: \chi^{2}=8.542, \mathrm{p}<.01 ; \mathrm{T} 15: \chi^{2}=5.775, \mathrm{p}<.02\right)$ show a significant contingency between suppliance of an article and whether first or subsequent mention is concerned, in the direction predicted by Trenkic.

\section{Table 5 here.}

\section{Discussion}

To summarize, Turkish-speaking learners of English at various proficiency levels have revealed linguistic behaviour most consistent with an account of interlanguage articles in terms of prosodic transfer. An analysis simply in terms of overt suppliance might have given the 
misleading impression that many of our subjects' representations of articles are relatively unproblematic, since the majority of them supply articles more often than not. By dividing overt articles into unstressed and stressed, we have been able to show that deletion is not the only strategy which learners adopt to circumvent the target English representation. While omission of L2 articles can in principle be explained on other accounts, the relatively high level of stressed articles is not susceptible to explanations that do not invoke prosody. There is no morphological, syntactic or semantic reason to stress articles; ${ }^{18}$ hence, this finding supports a phonological approach to the interlanguage representation of functional structure, in particular the PTH. With respect to the production of target-like articles, several subjects show a higher incidence of article deletion or stressing in DPs containing adjectives, suggesting that unstressed articles, at least for these subjects, do not involve the target L2 representation (in (3a)) and, instead, are represented by means of the L1 representation (in (3b)). Of course, articles should always be produced as stressed if they are indeed adjectives (as Trenkic maintains) because they must form independent PWds (section 2.2), something which is not observed in our data. In other words, the observation that stressed and unstressed articles co-occur in our data goes unexplained on Trenkic's account.

The syntactic misanalysis proposal of Trenkic expects article omission to be particularly robust in adjectival contexts because of communication pressure. Thus, finding higher instances of article omission in the context of adjectives does not serve to differentiate between Trenkic's proposal and the PTH, although higher incidence of other non-target strategies, such as stress, does. However, we have shown that several other predictions of the syntactic misanalysis account are not supported in our data, namely that articles should be omitted more when new information is involved and that indefinite articles should be omitted more than definite. ${ }^{19}$ The absence of such findings suggests that syntactic misanalysis is not implicated here. In short, the

\footnotetext{
${ }^{18}$ Of course, articles under focus are stressed in English, but the contexts in which the learners produced stressed articles in our experiment were not ones where stressing would normally be appropriate.

${ }^{19}$ Although we do not find greater omission of indefinites in the present study, we did find this pattern with SD (see White 2003; Goad \& White 2004).
} 
only explanation which accounts for the cluster of phenomena we have found (omission, stressing, substitution, differential treatment of articles before adjectives) is provided by the PTH.

It should be noted that the PTH does not exclude the possibility of multiple influences on L2 article production (see White 2007). For example, there might be semantic or discourse factors involved as well as phonological ones, which could explain why a few of the subjects did omit indefinite articles more than definite, for example. In contrast, according to Trenkic, the syntactic misanalysis account explains all aspects of L2 article production, the claim being that the misanalysis of adjectives as articles can explain the phenomena argued by Goad \& White (2004) to be prosodic. In other words, Trenkic aims to replace the PTH as opposed to supplementing it. Our results provide evidence against this position.

Finally, we consider the implications of our findings for the question of whether or not L1-based prosodic representations are permanent. Although as originally proposed (Goad, White \& Steele 2003), the PTH might be seen as a phonological version of the RDH, that is, that L2 speakers cannot appropriately modify L1 prosodic representations in response to L2 input, in subsequent work (Goad \& White 2004), we found evidence for restructuring under the two conditions in (9). In Goad \& White (2006b), we predicted that ultimate attainment of appropriate L2 prosodic representations will differ depending on how the particular functional material must be organized, as an affixal clitic (usually acquirable under the conditions in (9)) or as a free clitic (usually not acquirable under the conditions in (9)). For the case under discussion, the necessary structure for English articles is not acquirable under either of the conditions in (9) (see section 3.1). However, the results from $\mathrm{T} 13, \mathrm{~T} 1$ and $\mathrm{T} 2$ indicate that new prosodic structures can in fact be built under conditions other than those in (9), thereby providing support for a weaker interpretation of the PTH. Three subjects of intermediate proficiency (T16, T15, T9) also appear to be in the process of acquiring the target representation for English articles, while at the same time showing considerable L1 effects. 
In conclusion, since we do have some evidence that target prosodic representations are acquirable in L2 under conditions other than those in (9), this suggests that the PTH is the prosodic equivalent of Full Transfer Full Access (FTFA) (Schwartz \& Sprouse 1996) rather than the RDH or other Full Transfer Partial Access models (see White 2003b). We note that development in the phonological domain lags behind the syntactic domain as far as article acquisition is concerned. In the sub-domain of prosodic phonology, the explanation for this is presumably that learners must acquire the syntax of new functional material before they can begin to figure out how to organize it prosodically. Given that the same morpho-syntactic element can be prosodified in different ways across grammars (e.g., prepositions in different NeoŠtokavian dialects of Serbo-Croatian (Zec 1993)), within a single grammar depending on prosodic criteria (e.g., determiners in Standard Serbian (Zec 2005)), or within a single grammar depending on syntactic considerations (e.g., presence or absence of focus; final versus non-final position in the phrase (e.g., Selkirk 1996)), the presence of a lag in the acquisition of prosodic phonology is not surprising. 


\section{References}

Abney, S. 1987. The English Noun Phrase in its Sentential Aspect. PhD dissertation, MIT.

Beck, M.-L. 1998. L2 acquisition and obligatory head movement: English-speaking learners of German and the local impairment hypothesis. Studies in Second Language Acquisition 20: 311-348.

Duffield, N., White, L., Bruhn de Garavito, J., Montrul, S. and Prévost, P. 2002. Clitic placement in L2 French: Evidence from sentence matching. Journal of Linguistics 38: 487-525.

Erguvanli, E. E. 1984. The Function of Word Order in Turkish Grammar. Berkeley: University of California Press.

Eubank, L. 1996. Negation in early German-English interlanguage: More valueless features in the L2 initial state. Second Language Research 12: 73-106.

Franceschina, F. 2001. Morphological or syntactic deficits in near-native speakers? An assessment of some current proposals. Second Language Research 17: 213-247.

Fry, D. 1958. Experiments in the perception of stress. Language and Speech 1: 126-152.

Goad, H. and White, L. 2004. Ultimate attainment of L2 inflection: Effects of L1 prosodic structure. In EUROSLA Yearbook 4, S. Foster-Cohen, M. Sharwood Smith, A. Sorace and M. Ota (eds), 119-145. Amsterdam: John Benjamins.

Goad, H. and White, L. 2006a. Prosodic transfer: L1 effects on the production of L2 determiners. In Proceedings of the 30th Annual Boston University Conference on Language Development, D. Bamman, T. Magnitskaia and C. Zaller (eds), 213-224. Somerville, MA: Cascadilla Press.

Goad, H. and White, L. 2006b. Ultimate attainment in interlanguage grammars: A prosodic approach. Second Language Research 22: 243-268. 
Goad, H. and White, L. In press. Prosodic structure and the representation of L2 functional morphology: A nativist approach. Lingua.

Goad, H., White, L. and Steele, J. 2003. Missing inflection in L2 acquisition: Defective syntax or L1-constrained prosodic representations? Canadian Journal of Linguistics 48: 243-263.

Hawkins, R. 2000. Persistent selective fossilisation in second language acquisition and the optimal design of the language faculty. Essex Research Reports in Linguistics 34: 75-90.

Hawkins, R. 2003. 'Representational deficit' theories of (adult) SLA: Evidence, counterevidence and implications. Plenary paper presented at EUROSLA, Edinburgh, Sept.

Hawkins, R., Al-Eid, S., Almahboob, I., Athanasopoulos, P., Chaengchenkit, R., Hu, J., Rezai, M., Jaensch, C., Jeon, Y., Jiang, A., Leung, Y.-k.I., Matsunaga, K., Ortega, M., Sarko, G., Snape, N. and Velasco-Zárate, K. 2006. Accounting for English article interpretation by L2 speakers. In Eurosla Yearbook 6, S. Foster-Cohen, M.M. Krajnovic and J.M. Djigunovic (eds), 7-25. Amsterdam: John Benjamins.

Hawkins, R. and Chan, C. Y-H. 1997. The partial availability of Universal Grammar in second language acquisition: The 'Failed Functional Features Hypothesis'. Second Language Research 13: 187-226.

Hawkins, R. and Liszka, S. 2003. Locating the source of defective past tense marking in advanced L2 English speakers. In The Interface between Syntax and Lexicon in Second Language Acquisition, R. van Hout, A. Hulk, F. Kuiken and R. Towell (eds), 21-44. Amsterdam: John Benjamins.

Huebner, T. 1985. System and variability in interlanguage syntax. Language Learning 35: 141163. 
Hulst, H. van der and Weijer, R. van de. 2004. Vowel harmony. In The Handbook of Phonological Theory, J. Goldsmith (eds), 495-534. Oxford: Blackwell.

Inkelas, S. and Orgun, C.O. 2003. Turkish stress: a review. Phonology 20: 139-161.

Ionin, T. 2003. Article Semantics in Second Language Acquisition. PhD dissertation, MIT.

Ionin, T., Ko, H. and Wexler, K. 2004. Article semantics in L2 acquisition: The role of specificity. Language Acquisition 12: 3-69.

Kabak, B. and Vogel, I. 2001. The phonological word and stress assignment in Turkish. Phonology 18: 315-360.

Konrot, A.K. 1981. Physical correlates of linguistic stress in Turkish. University of Essex Language Centre Occasional Papers 24: 26-53.

Kornfilt, J. 1997. Turkish. London: Routledge.

Kupisch, T., Anderssen., M., Bohnacker, U. and Snape, N. To appear. Article acquisition in German, English, Norwegian and Swedish. Proceedings of the Georgetown University Round Table on Languages and Linguistics.

Lardiere, D. 1998. Dissociating syntax from morphology in a divergent end-state grammar. Second Language Research 14: 359-375.

Lehiste, I. 1976. Influence of fundamental frequency pattern on the perception of duration. Journal of Phonetics 4: 113-117.

Leung, Y.-k.I. 2002. Functional Categories in Second and Third Language Acquisition: A Crosslinguistic Study of the Acquisition of English and French by Chinese and Vietnamese Speakers. PhD dissertation, McGill University.

Levi, S.V. 2005. Acoustic correlates of lexical accent in Turkish. Journal of the International Phonetic Association 35: 73-97. 
Lyons, C. 1999. Definiteness. Cambridge: Cambridge University Press.

Newell, H. 2005. The phonological phase. In R. Mercado and Y. Furukawa (eds), McGill Working Papers in Linguistics 19: 21-63.

Öztürk, B. 2005. Case, referentiality and phrase structure. Amsterdam: John Benjamins. Peperkamp, S. 1997. Prosodic Words. The Hague: Holland Academic Graphics.

Poser, W.J. 1990. Word-internal phrase boundary in Japanese. In The Phonology-Syntax Connection, S. Inkelas and D. Zec (eds), 279-287. Chicago: University of Chicago Press.

Robertson, D. 2000. Variability in the use of the English article system by Chinese learners of English. Second Language Research 16: 135-172.

Schwartz, B. D. and R. Sprouse. 1996. L2 cognitive states and the full transfer/full access model. Second Language Research 12: 40-72.

Selkirk, E.O. 1996. The prosodic structure of function words. In Signal to Syntax, J.L. Morgan and K. Demuth (eds), 187-213. Mahwah, NJ: Lawrence Erlbaum.

Sezer, E. 1981. On non-final stress in Turkish. Journal of Turkish Studies 5: 61-69.

Snape, N. 2006. The Acquisition of the English Determiner Phrase by Japanese and Spanish Learners of English. PhD dissertation, University of Essex.

Thomas, M. 1989. The acquisition of English articles by first- and second-language learners. Applied Psycholinguistics 10: 335-355.

Trenkic, D. 2004. Definiteness in Serbian/Croatian/Bosnian and some implications for the general structure of the nominal phrase. Lingua 114: 1401-27.

Trenkic, D. 2007. Variability in L2 article production - beyond the representational deficit vs. processing constraints debate. Second Language Research 23: 289-327. 
Trenkic, D. In press. The representation of English articles in second language grammars: Determiners or adjectives. Bilingualism: Language and Cognition.

Tsimpli, I.M. 2003. Clitics and determiners in L2 Greek. In Proceedings of the 6th Generative Approaches to Second Language Acquisition Conference (GASLA 2002): L2 Links, J.M. Liceras, H. Zobl and H. Goodluck (eds), 331-339. Somerville, MA: Cascadilla Press.

Tsimpli, I.M. and Mastropaviou, M. 2007. Feature interpretability in L2 acquisition and SLI: Greek clitics and determiners. In The role of formal features in second language acquisition, J. Liceras, H. Zobl and H. Goodluck (eds), 143-183. New York: Lawrence Erlbaum.

Tsimpli, I.M. and Roussou, A. 1991. Parameter resetting in L2? UCL Working Papers in Linguistics 3: 149-169.

Underhill, R. (1976). Turkish grammar. Cambridge, MA: MIT Press.

White, L. 2003a. Fossilization in steady state L2 grammars: Persistent problems with inflectional morphology. Bilingualism: Language and Cognition 6: 129-141.

White, L. 2003b. Second language acquisition and Universal Grammar. Cambridge: Cambridge University Press.

White, L. 2007. Some puzzling features of L2 features. In The role offormal features in second language acquisition, J. Liceras, H. Zobl and H. Goodluck (eds), 301-326. New York: Lawrence Erlbaum.

Zec, D. 1993. Rule domains and phonological change. In Studies in Lexical Phonology, S. Hargus and E. Kaisse (eds), 365-405. San Diego: Academic Press.

Zec, D. 2005. Prosodic differences among function words. Phonology 22: 77-112. 


\begin{tabular}{|l|c|c|c|c|c|c|}
\hline & omission & stressing & substitution & adj problems & indef $>$ def & old info \\
\hline PTH & $\sqrt{ }$ & some & $\sqrt{ }$ & $\sqrt{ }$ & & \\
\hline Art as adj & $\sqrt{ }$ & all & & $\sqrt{ }$ & $\sqrt{ }$ & $\sqrt{ }$ \\
\hline
\end{tabular}

Table 1. Predictions of PTH and syntactic misanalysis

\begin{tabular}{|c|c|c|c|}
\hline $\begin{array}{c}\text { Target-like performance on } \\
\text { DPs without adjectives }\end{array}$ & Contigency on \pm adj & No contigency & $\begin{array}{c}\text { Not enough DPs with } \\
\text { adjectives }\end{array}$ \\
\hline $0-49 \%$ & T10, T11, T7, T8, (T14) & T16 & T18, T17, T5, T12, T4 \\
\hline $50-69 \%$ & $\mathrm{~T} 3, \mathrm{~T} 6$ & $\mathrm{~T} 15, \mathrm{~T} 9$ & \\
\hline $70-100 \%$ & & $\mathrm{~T} 13, \mathrm{~T} 1, \mathrm{~T} 2$ & \\
\hline
\end{tabular}

Table 2. Contingency or no contingency on \pm adjective

\begin{tabular}{|c|c|c|c|c|c|c|c|c|c|c|c|c|c|c|c|c|c|c|}
\hline & \multicolumn{9}{|c|}{ Low } & \multicolumn{7}{|c|}{ Intermediate } & \multicolumn{2}{|c|}{ High } \\
\hline & T18 & $\mathrm{T} 10$ & $\mathrm{~T} 11$ & $\mathrm{~T} 17$ & T5 & \begin{tabular}{|l} 
T12 \\
T
\end{tabular} & $\mathrm{T} 4$ & $\mathrm{~T} 7$ & \begin{tabular}{|l|l|} 
T14 \\
T1
\end{tabular} & $\mathrm{T} 16$ & $\mathrm{~T} 8$ & $\mathrm{~T} 15$ & $\mathrm{~T} 3$ & T9 & $\mathrm{T} 13$ & $\mathrm{~T} 1$ & T6 & $\mathrm{T} 2$ \\
\hline of $a$ & $2 / 37$ & $11 / 45$ & $8 / 33$ & $12 / 49$ & $10 / 33$ & $8 / 48$ & $20 / 31$ & $3 / 25$ & $8 / 55$ & $22 / 61$ & 28/91 & $4 / 34$ & $9 / 83$ & $1 / 46$ & $0 / 32$ & $4 / 65$ & $4 / 46$ & $10 / 73$ \\
\hline & $/ 24$ & $27 / 43$ & $19 / 26$ & $20 / 60$ & $11 / 40$ & $10 / 33$ & 7/34 & $12 / 51$ & $18 / 78$ & $16 / 77$ & $23 / 112$ & $13 / 39$ & $12 / 90$ & $8 / 75$ & $25 / 120$ & $7 / 97$ & $11 / 71$ & $4 / 100$ \\
\hline $\begin{array}{l}\% \text { zero } \\
\text { indef }\end{array}$ & 59 & 24 & 24 & 24 & 30 & 17 & 65 & 12 & 15 & 36 & 31 & 12 & 11 & 2 & 0 & 6 & 9 & 14 \\
\hline$\%$ zero def & 83 & 63 & 73 & 33 & 28 & 30 & 21 & 24 & 23 & 21 & 21 & 33 & 13 & 11 & 21 & 7 & 15 & 4 \\
\hline
\end{tabular}

Table 3. Omission of definite and indefinite articles in obligatory contexts 


\begin{tabular}{|l|c|c|c|c|c|c|c|c|c|c|c|c|c|c|c|c|c|c|}
\hline & \multicolumn{9}{|c|}{ Low } & \multicolumn{1}{c|}{ Intermediate } & \multicolumn{3}{c|}{ High } \\
& $\mathrm{T} 18$ & $\mathrm{~T} 10$ & $\mathrm{~T} 11$ & $\mathrm{~T} 17$ & $\mathrm{~T} 5$ & $\mathrm{~T} 12$ & $\mathrm{~T} 4$ & $\mathrm{~T} 7$ & $\mathrm{~T} 14$ & $\mathrm{~T} 16$ & $\mathrm{~T} 8$ & $\mathrm{~T} 15$ & $\mathrm{~T} 3$ & $\mathrm{~T} 9$ & $\mathrm{~T} 13$ & $\mathrm{~T} 1$ & $\mathrm{~T} 6$ & $\mathrm{~T} 2$ \\
\hline $\begin{array}{l}\text { \% overt article, } \\
\text { subject }\end{array}$ & 0 & 27 & 0 & 71 & 76 & 73 & 86 & 74 & 94 & 73 & 82 & 71 & 94 & 89 & 100 & 94 & 88 & 100 \\
\hline $\begin{array}{l}\text { \% overt article, } \\
\text { non subject }\end{array}$ & 6 & 59 & 52 & 71 & 77 & 79 & 61 & 83 & 77 & 69 & 70 & 75 & 87 & 93 & 79 & 93 & 91 & 90 \\
\hline
\end{tabular}

Table 4. Suppliance of articles and topic status (in \%)

\begin{tabular}{|l|c|c|c|c|c|c|c|c|c|c|c|c|c|c|c|c|c|c|}
\hline & \multicolumn{1}{|c|}{ Low } & \multicolumn{1}{c|}{ Intermediate } & \multicolumn{2}{c|}{ High } \\
& $\mathrm{T} 18$ & $\mathrm{~T} 10$ & $\mathrm{~T} 11$ & $\mathrm{~T} 17$ & $\mathrm{~T} 5$ & $\mathrm{~T} 12$ & $\mathrm{~T} 4$ & $\mathrm{~T} 7$ & $\mathrm{~T} 14$ & $\mathrm{~T} 16$ & $\mathrm{~T} 8$ & $\mathrm{~T} 15$ & $\mathrm{~T} 3$ & $\mathrm{~T} 9$ & $\mathrm{~T} 13$ & $\mathrm{~T} 1$ & $\mathrm{~T} 6$ & $\mathrm{~T} 2$ \\
\hline $\begin{array}{l}\text { \% overt article, } \\
\text { first mention }\end{array}$ & 38 & 69 & 64 & 75 & 71 & 80 & 52 & 79 & 81 & 73 & 70 & 83 & 87 & 95 & 79 & 95 & 89 & 88 \\
\hline $\begin{array}{l}\text { \% overt article } \\
\text { subsequent }\end{array}$ & 14 & 28 & 20 & 54 & 68 & 67 & 65 & 85 & 81 & 68 & 81 & 56 & 92 & 89 & 98 & 88 & 89 & 100 \\
\hline
\end{tabular}

Table 5. Suppliance of articles and first vs. subsequent mention (in \%) 


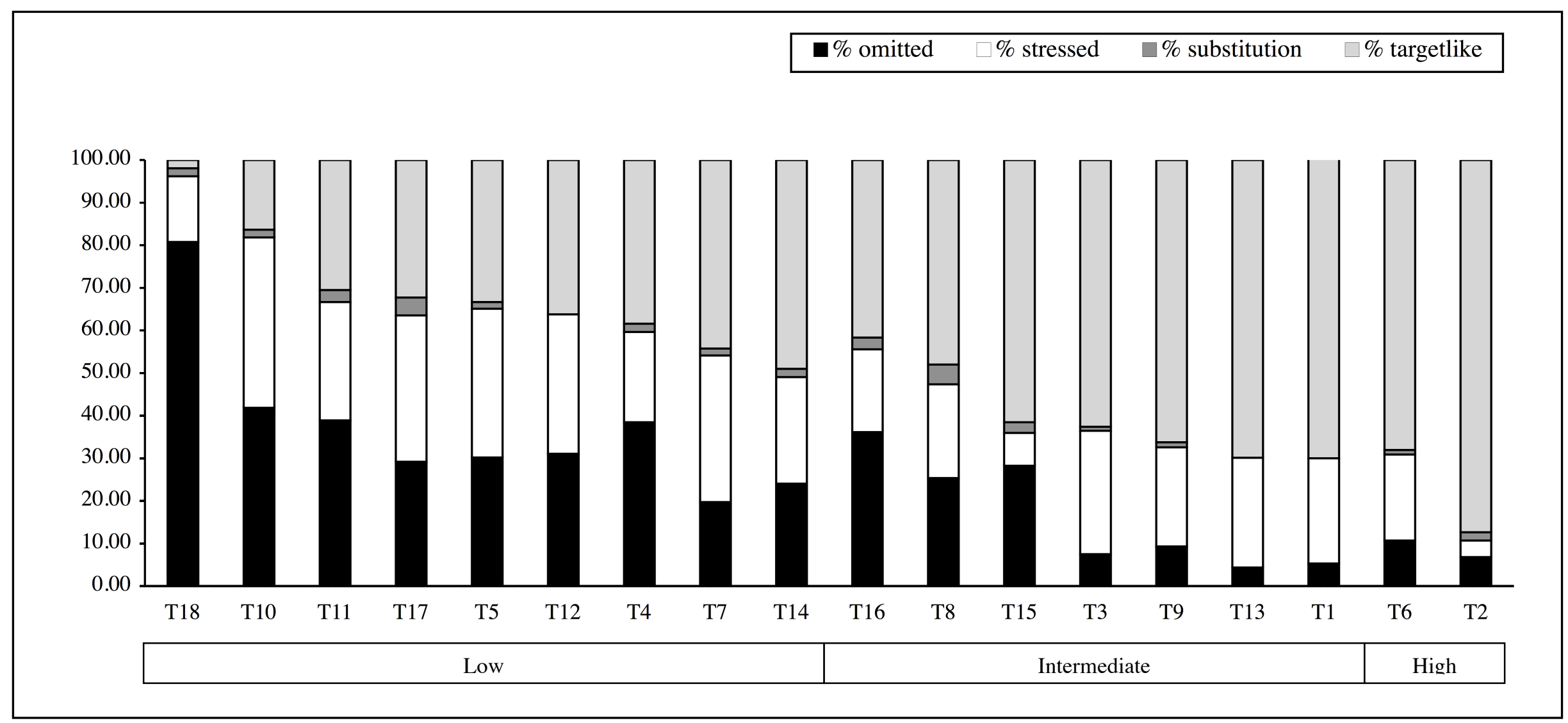

Figure 1. Patterns of article suppliance for DPs without adjectives 


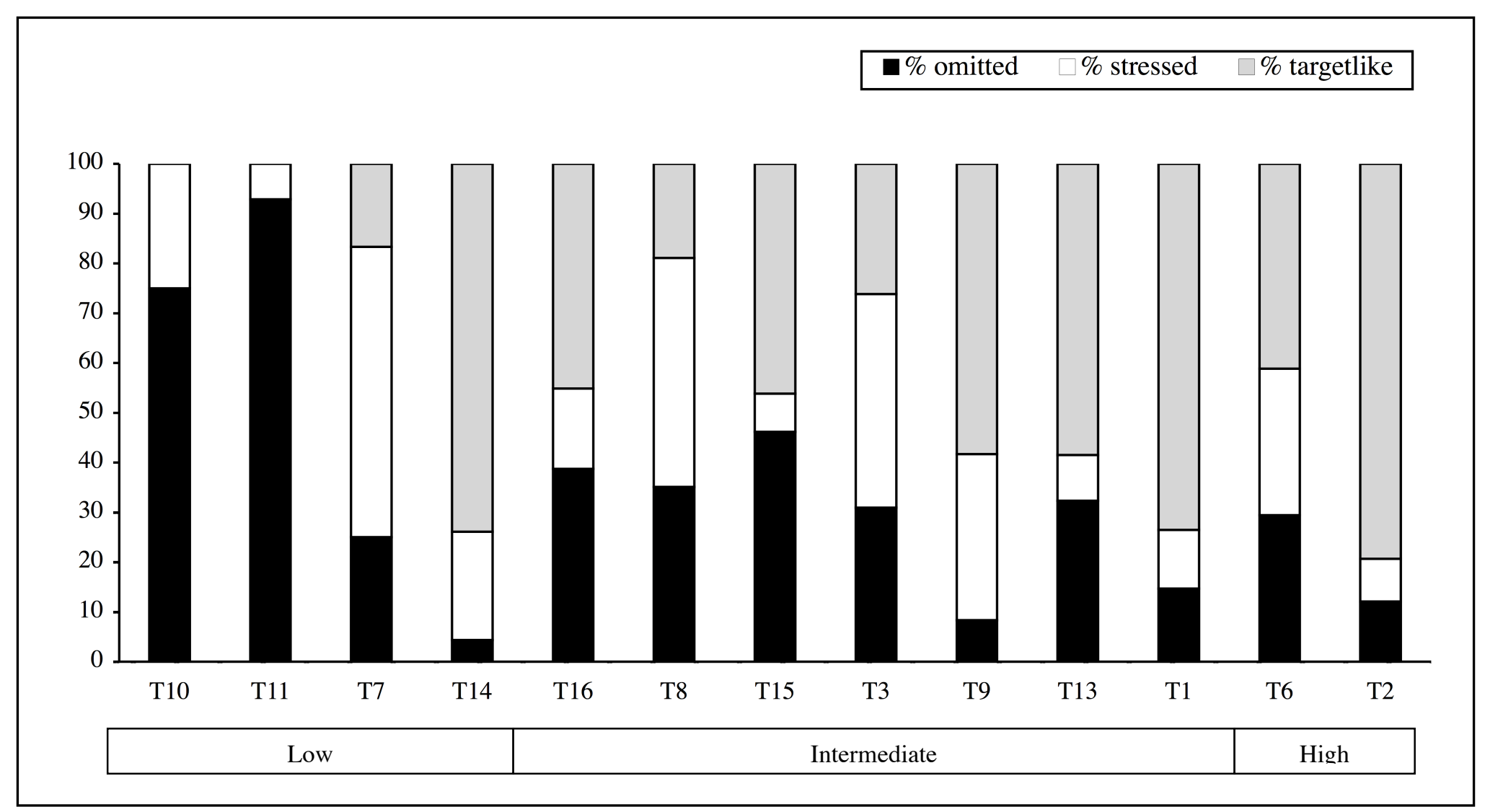

Figure 2. Patterns of article suppliance for DPs containing adjectives 